Article

\title{
Simultaneous Analysis of Heavy Metal Concentration in Soil Samples
}

\author{
Anna Śliwińska, Adam Smolinski *(1) and Piotr Kucharski \\ Central Mining Institute, 40-166 Katowice, Poland; asmolinski@gig.katowice.pl (A.Ś.); pkucharsik@gig.eu (P.K.) \\ * Correspondence: smolin@gig.katowice.pl; Tel.: +48-32259-22-52
}

Received: 2 October 2019; Accepted: 1 November 2019; Published: 4 November 2019

check for updates

\begin{abstract}
The application of Fourier transform infrared spectroscopy to the simultaneous analysis of heavy metal concentration in soil samples was demonstrated in this paper. Two spectral techniques, namely, attenuated total reflectance (ATR) and diffuse reflectance (DRIFT), were applied and the whole infrared spectral region, i.e., far IR, mid IR, and near IR were considered in this work. Spectral data with reference to the results of laboratory analysis enabled the development of calibration partial least squares (PLS) models. The PLS models for the ATR near IR were characterized by a good fit and good prediction abilities. According to the results obtained, the most accurate description and prediction were realized in the case of mid/far and near IR for the mercury and nickel concentration in soil. Application of far IR slightly improved the prediction possibilities of the model. The construction of PLS models based on the Fourier-transform infrared (FT-IR) spectra enables the perception of FT-IR spectroscopy as a supplementary method that is useful in the estimation and monitoring of the contamination level in soils.
\end{abstract}

Keywords: soil pollution; FTIR spectra; partial least squares PLS; far-IR; rapid estimation

\section{Introduction}

The assessment of the degree of soil pollution with heavy metals is still a serious challenge for scientific departments dealing with this problem. The recognition of areas potentially contaminated with heavy metals is legally sanctioned in many countries. An exemplary document that is in force in the European Union is Directive No. 2010/75/EU [1] and the resulting Regulation (Dz.U. 2016 poz. 1395 (2016) in Polish law) [2]. A typical procedure for determining the degree of contamination of soil is based on sampling in accordance with the designated grid, an analysis of the contamination levels in the laboratory, and the interpretation of test results based on geostatistical methods. Commonly used methods for determining heavy metal content, such as inductively coupled plasma optical emission spectrometry [3], are time-consuming and expensive. In the case of the need to recognize the scale of pollution of a large area, the cost and time needed to perform the necessary research increases significantly. In connection with the above, potential use of infrared spectroscopy as a new, less time-consuming, and less expensive method for determining the physicochemical parameters of soils has been studied for several years.

Infrared spectroscopy is a useful tool for investigating soil parameters such as total carbon, total nitrogen, the $\mathrm{C} / \mathrm{N}$ ratio, lignin, dissolved $\mathrm{OC}$, carbonyl-C, aromatic- $\mathrm{C}$, O-alkyl-C, and alkyl-C contents. A review of the applications of Fourier-transform infrared (FT-IR) spectroscopy for the analysis of soil samples was presented by Tinti et al. [4]. Nocita et al. [5] presented the state of the art in the field of the application of infrared spectroscopy in soil analyses as an alternative to traditional so-called "wet" methods. The authors considered both the advantages and limits of this technique. Shepherd and Walsh [6] presented a review of the application of infrared spectroscopy to agricultural and environmental management. 
Previous studies have shown various possible applications of infrared spectroscopy for soil analysis. Viscarra Rossel et al. [7] examined different soil properties, including $\mathrm{pH}$, organic carbon, slay, silt, sand, cation exchange capacity, exchangeable calcium, exchangeable aluminum, nitrate nitrogen, available phosphorus, exchangeable potassium, and electrical conductivity. The authors compared PLS calibration models based on spectra obtained using the technique of diffuse reflectance (DRIFT) both separately and jointly in different infrared regions. $\mathrm{Ng}$ et al. [8] evaluated the use of field portable and laboratory benchtop infrared spectrometers in the range of near infrared (NIR) and mid infrared (MIR) for the rapid nondestructive assessment of petroleum-contaminated soils. FT-IR has also been used for the analysis of the heavy metal concentration in soils. Chodak et al. [9] studied the ability of near-infrared spectroscopy to detect the effects of heavy metals on the chemical composition of forest soil. The authors underlined that some concentrations (especially high concentrations) of heavy metals obtained using NIR spectroscopy were lower than in reality due to the fact that heavy metals in industrial samples are partially present in the inorganic form. Similar results were obtained by Siebielec et al. [10] for soil metal content in highly contaminated soil samples obtained from industrial regions. The authors concluded that using mid-infrared lead to more accurate models compared to NIR. Gholizadeh et al. [11] assessed the usefulness of the VIS-NIR method in the monitoring of toxic elements in soil samples from reclaimed dumpsites. Chen et al. [12] applied visible and near infrared for fast analysis of cadmium pollution of soils. Niazi et al. [13] used the DRIFT mode in the MIR range combined with PLS to estimate the contamination of soil with arsenic. Chakraborty et al. [14] used Mid-IR and the DRIFT mode in combination with artificial neural network (ANN) models to assess lead concentration in soil samples collected from an urban landfill agricultural site.

Infrared spectroscopy has shown great potential for use in the analysis of different soil properties and contamination levels, but the problem of a choice of the optimal measurement methodology remains unresolved. The choice of the infrared range is important problem in the area of spectral soil analyses. Equally important question refers to the important issue of representativeness of samples for spectral analyses and comparison of the measurements in the laboratory after sample preparation or directly in the field (in-situ). Other issues relate to the choice of spectral techniques, the impact of the variation of the material studied on the results, or the choice of chemometric techniques to create a prediction model.

It was indicated that spectral analysis in the mid infrared region enables one to obtain more accurate models than in the near infrared region [15]; however, visible and near infrared radiation (VIS-NIR) has been usually considered for application in on-line measurements. Jiminez-Donaire et al. [16] presented an application of a diffuse reflectance mode and PLS calibration model in the on-line measurement of moisture content, soil organic carbon, $\mathrm{pH}$, and total nitrogen. The specially designed on-line measurement system was mounted onto a tractor, with spectral data collected while moving across the landscape with a velocity of $2 \mathrm{~km} / \mathrm{h}$. He et al. [17] used near-infrared reflectance spectroscopy for the estimation of nitrogen and organic matter content in soil samples. The authors indicated that this is a useful rapid technique for in situ application, which can be combined with GIS. Additionally, Martin et al. [18] used near-infrared spectroscopy for a rapid analysis of organic carbon and nitrogen within a single field. This method was useful for analyzing carbon content in a range of $0-40 \mathrm{mg} / \mathrm{g}$, however, the authors reported that they did not succeed in determining the nitrogen concentration. On the other hand, recent technological development of semiconductor technologies contributes in the development of mid-infrared (mid-IR) portable spectrometers.

Reeves J.B. [19] compared the application of near and mid infrared in soil analyses and their related advantages and disadvantages. They also considered several questions concerning laboratory and on-site analysis, the effect of moisture and particle size on accuracy, and the effect of different soil types and compositions on calibration. He stated that DRIFT is not useful in on-site application but is advantageous in the laboratory after sample drying and grounding. D'Acqui et al. [20] described an exemplary procedure of sampling for application of mid-infrared diffuse reflectance Fourier transform (MIR-DRIFT) spectroscopy, with partial least squares (PLS) regression, for the determination of 
variations in soil properties. After removal of the debris from the surface (twigs, litter, and rocks), the samples were taken from the surface to a depth of $20 \mathrm{~cm}$, then for analysis were dried at $40{ }^{\circ} \mathrm{C}$, and ground by a mill and sieved to $<100 \mu \mathrm{m}$ particle diameter. The authors collected 198 samples, and to obtain each representative sample, three subsamples were collected and mixed. Application of different techniques of mid infrared spectroscopy: diffuse reflectance spectroscopy, attenuated total reflectance spectroscopy, and Fourier transform infrared photoacoustic spectroscopy (PAS) for investigation of soil properties was analyzed and compared by Ma et al. [21].

Raw spectra are often processed before use as an input into a chemometric model development using various techniques, such as absorbance transformation $\log (1 / \mathrm{R})$, mean centering, detrend, standard normal variate (SNV), Savitzky-Golay smoothing, first or second derivatives, and multiplicative scatter correction (MSC) $[7,11]$. A review of the spectral preprocessing methods is presented by Tinti et al. [4] and Chen et al. [12]. The methods that are frequently combined with infrared spectroscopy are partial least square regression (PLS), principal component analysis (PCA), and artificial neural networks (ANN).

A literature review showed that extensive research was performed in the field of spectral rapid assessment of soil properties, especially with emphasis on properties that are important for agriculture-organic matter content, nitrogen content, $\mathrm{pH}$ etc. A much narrower group of papers considered heavy metal concentration in soil. Measurements were conducted on NIR, Vis-NIR, and less often on MIR. The far-IR region was not investigated in term of its usefulness for soil metal analysis. Frequencies of oscillations of heavy metal bonds are lower because of the mass. The crystal structure of inorganic compounds can be affected in the presence of heavier cations. Thus, analyzing the possibility of use of the FIR region for metal concentration analysis is justified.

The aim of this paper was construction of the PLS models for simultaneous analysis of various heavy metal concentrations in soil samples based on FT-IR spectra. Two spectral techniques, namely ATR and DRIFT, as well as the whole infrared region, were investigated during the study. Accuracy and prediction abilities of models were compared for as many as 13 harmful metals. Samples were taken from the polluted area, thus the range of concentrations of metals is very large. Moreover in this paper, the region of far-IR spectroscopy was considered as the method to improve the detection of heavy metals in soil. According to the knowledge of the authors, this region had not been investigated before in terms of soil metal concentration prediction.

\section{Materials and Methods}

\subsection{Samples}

The soil material used in the IR studies was selected from samples taken in the vicinity of the copper smelter "Głogów" (Poland) (Figure 1). Samples were collected according to the PN-ISO 10381-5 standard. The collected samples were air-dried and sieved through a 2-mm sieve to separate the coarse fraction. The fine fraction was homogenized, ground in a planetary mill (zirconium oxide grinding bowl), and passed through a $200-\mu \mathrm{m}$ sieve. The coarse fraction was discarded. Selected physicochemical parameters were determined in the Laboratory of Solid Waste Analyses, Central Mining Institute, Poland. Mercury content was determined by CVAAS (MA2000, NIC) according to an internal procedure SC-1.PB.23. The remaining trace elements were determined by ICP-OES (Optima 5300DV, PerkinElmer), after microwave mineralization in aqua regia, according to internal procedure SC-1.PB.11. 


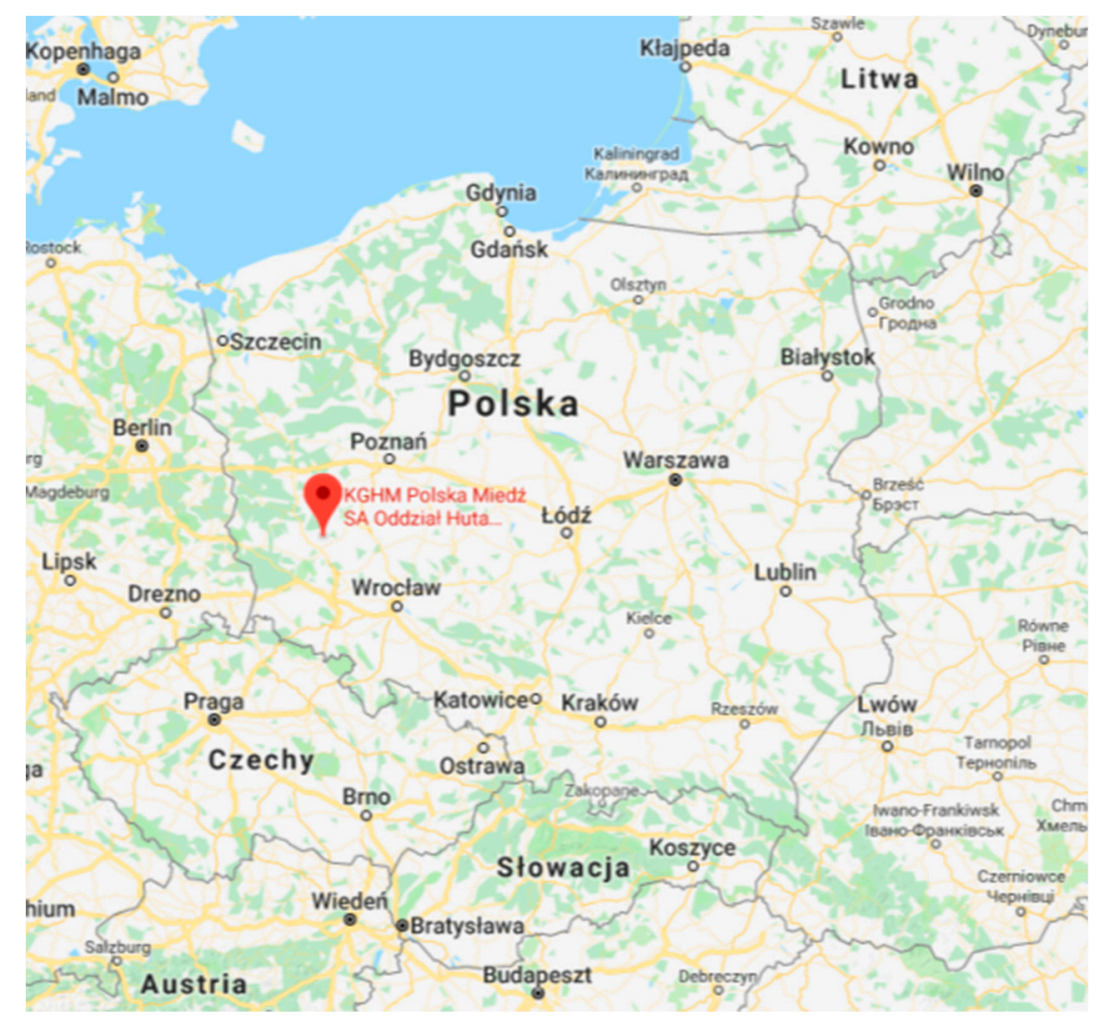

Figure 1. The location of the copper smelter “Głogów” (Source: Google Map).

\subsection{Fourier Transform Infrared Spectroscopy}

FTIR analyses of the 100 soil samples were carried out in the laboratory of Central Mining Institute (Katowice, Poland) using a Thermo Scientific Nicolet iS50 spectrometer. Spectral analyses were performed using samples prepared according to the procedure described earlier: dried, grounded and sieved. Two spectral techniques based on attenuated total reflectance and diffuse reflectance were applied to samples, as these techniques enable direct measurements of the surface of solid samples without a need for pellet preparation; thus, potential application of these techniques in rapid estimation is considered. The first technique, the attenuated total reflectance (ATR) was used in the far infrared (FIR) range. The Nicolet iS50 FT-IR spectrometer has built-in diamond iS50 ATR sampling station. A sample was placed on a crystal diamond and then pressed onto the top surface of the crystal. In this technique, the attenuated reflectance is measured. During the measurement, the infrared radiation propagates through the crystal with such an angle that enables one to obtain internal reflectance. Infrared radiation is reflected but penetrates into the surface of a sample pressed onto the crystal. The second technique, the diffuse reflectance infrared Fourier Transform (DRIFT) technique, was used in the mid infrared (MIR) range. The absorption and scattering of light by the sample in all directions (diffuse reflectance) was measured in the DRIFT technique. Samples were placed in a stainless steel cup, located in a diffuse reflectance accessory and scanned. The spectrometer was equipped with a DLaTGS (deuterated L-alanine doped triglycene sulphate) detector and a KBr beam splitter for mid IR and solid substrate for far IR. In the near IR region, a Thermo Scientific NIR Integrating Sphere equipped with an InGaAs detector and $\mathrm{CaF}_{2}$ beamsplitter was used. The sample was placed on the sapphire window. In the module, near-infrared energy passes through the window and is diffusely reflected by the sample. Then the reflected light is efficiently collected by the sphere and directed onto the dedicated InGaAs detector.

All spectra were collected after a nitrogen purge. The spectrum for air was used as a background in the ATR technique, and as a pure potassium bromide $(\mathrm{KBr})$ in the DRIFT and NIR techniques. The number of scans was set at 64 with a resolution of $4 \mathrm{~cm}^{-1}$. Spectra were measured over a far 
infrared range of $1800-100 \mathrm{~cm}^{-1}$, a mid-infrared range of $4000-400 \mathrm{~cm}^{-1}$, and a near-infrared range of $12,500-4000 \mathrm{~cm}^{-1}$. Data obtained from the laboratory analyses together with the collected spectra were used to develop and validate the partial least squares regression models. The spectra in the form of csv files were the input to the model created in MATLAB. Spectra were not modified before the development of PLS models.

\subsection{Spectral Preprocessing and PLS}

To find a relationship between the metal content in soils and the spectral properties of soils, multivariate calibration methods should be used. Partial least squares (PLS) is one of the most often used multivariate calibration methods [22-28], which can be used for data sets in which the measured parameters are intercorrelated. PLS overcomes the problem of correlated variables by constructing new orthogonal variables; this process maximizes the description of the covariance between $\mathbf{X}$ and $\mathbf{y}$. The proper complexity of the PLS model was determined based on cross-validation (CV) [29]. This means that the correct constructed PLS model should be characterized by a good fit to the data used for the model construction and good prediction abilities for new variables. For a correct assessment of the model fit to the data used for their construction as well as the model prediction abilities, the root mean square error (RMS) (see Equation (1)) and the root mean square error of cross validation (RMSCV) (Equation (2)) were calculated, respectively, as follows:

$$
R M S=\sqrt{\frac{\sum_{i=1}^{m}\left(y_{i}-\hat{y}_{i}\right)^{2}}{m}}
$$

where $y_{i}$ and $\hat{y}_{i}$. denote the experimental values for the dependent variable for a model set and their predicted values, respectively, while $m$ denotes the number of objects in the model set;

$$
\operatorname{RMSCV}(A)=\sqrt{\frac{\sum_{i=1}^{m}\left(y_{i}^{t}-\hat{y}_{*}^{t}(A)\right)^{2}}{m}}
$$

where $y_{i}{ }^{t}$ and $\hat{y}_{\cdot i}{ }^{t}(A)$ denote the values from the test set and their values provided by the model for the complexity $A$, respectively.

\section{Results}

\subsection{Qualitative Description of FT-IR Spectra}

Soil is very complex, it contains both inorganic components, such as silicates, carbonates, sulfates, nitrates, as well as phosphates, and organic compounds such as humic and fulvic acids. In Figure 2, an exemplary structure for the organic matter of soil is presented.

Bands related to various functional groups, such as phenolic, carbonyl, carboxylic, anhydrides, and nitrogen-containing groups, are expected in the infrared spectrum of a soil sample.

Spectra measured in the mid-infrared region represent fundamental vibration modes and enable one to identify different bonds and functional groups present in the sample. Spectra for all soils were found to be generally similar with differences resulting from the content of clay, quartz, organic compounds, and both fulvic and humic acids in the soils. Two exemplary Mid-IR spectra are presented in Figure 3. 


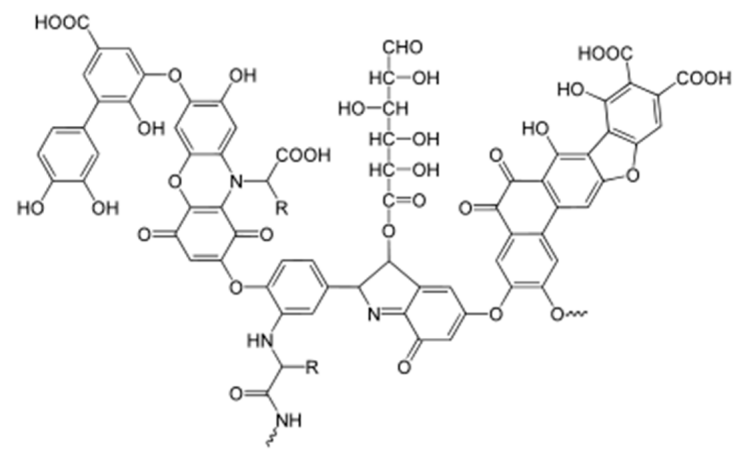

(a)

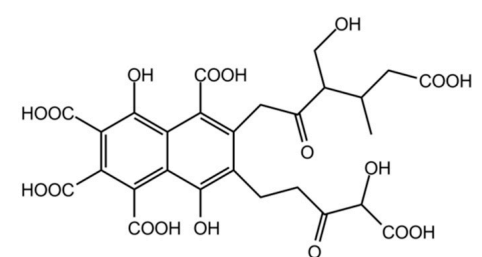

(b)

Figure 2. The hypothetical model structure for (a) humic acid and (b) fulvic acid.

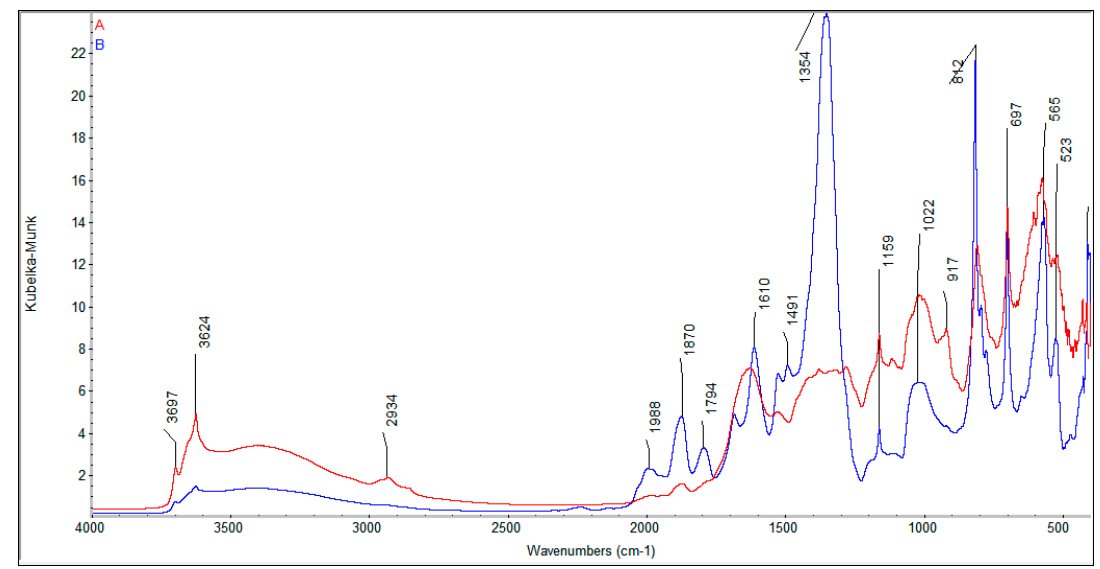

Figure 3. Exemplary soil spectra measured using the diffuse reflectance (DRIFT) technique in the mid infrared (MIR) region.

Bands due to the organic and inorganic compounds overlap; thus, their assignment to functional groups is difficult. However, some of them can be assigned to individual bonds and functional groups during a qualitative analysis of the spectra [4,30,31]. A broad band observed in the region from 3700 to $3000 \mathrm{~cm}^{-1}$ is related to the stretching of the associated H-bonded hydroxyl group in the $\mathrm{OH}$ group of alcohols and the Si-OH group. The peaks at 3697 and $3624 \mathrm{~cm}^{-1}$ are associated with vibrations of the Si-O-H bond. The peaks at approximately $2934 \mathrm{~cm}^{-1}$ are attributed to vibrations of aliphatic $\mathrm{CH}_{2}$ and the $\mathrm{CH}_{3}$ group. Vibrations of amides and aromatic $\mathrm{C}=\mathrm{C}$ bonds are observed in the region of 1700 to $\sim 1500 \mathrm{~cm}^{-1}$. The peak observed at $1988 \mathrm{~cm}^{-1}$ is connected to vibrations of cumulative $\mathrm{C}=\mathrm{C}$ bonds or aromatic $\mathrm{C}-\mathrm{H}$. The peaks at approximately 1870 and $1794 \mathrm{~cm}^{-1}$ can relate to anhydrides or the free $\mathrm{COOH}$ group. The peak with a maximum at $1610 \mathrm{~cm}^{-1}$ is related to vibrations of aromatic $C$ or conjugation of $C=C$ with the $C=O$ bond. The peak at $1159 \mathrm{~cm}^{-1}$ can be ascribed to the stretching vibrations of the $\mathrm{C}-\mathrm{O}$ bond in anhydrides, or $\mathrm{Si}-\mathrm{O}-\mathrm{C}$ and $\mathrm{Si}-\mathrm{O}-\mathrm{Si}$ in siloxanes. The peaks at approximately $1390 \mathrm{~cm}^{-1}$ and $917 \mathrm{~cm}^{-1}$ represent in plane and out of plane bending of the $\mathrm{OH}$ group. In the region 1400 to $950 \mathrm{~cm}^{-1}$, vibrations due to various bonds containing oxygen are observed, especially alcohols, phenols, ethers, acetates, and carbohydrates. Bands assigned to the vibration of silicates $\mathrm{SiO}_{4}{ }^{2-}$ are expected in the range $1100-900 \mathrm{~cm}^{-1}$, carbonates $\mathrm{CO}_{3}{ }^{2-}$ approximately $1450-1410$ and $880-800 \mathrm{~cm}^{-1}$, sulphates $\mathrm{SO}_{4}{ }^{2-}$ in the range $1130-1080 \mathrm{~cm}^{-1}$, nitrates $\mathrm{NO}_{3}{ }^{-}$in the range $1410-1340$ and $860-800 \mathrm{~cm}^{-1}$, and phosphates $\mathrm{PO}_{4}{ }^{3-}$ in the range $1100-900 \mathrm{~cm}^{-1}$ [30].

NIR and FIR spectra contain less information concerning the structure and functional groups. Bands observed in the near IR are mainly assigned to overtones and combinations of fundamental vibrational modes of groups containing $\mathrm{C}-\mathrm{H}, \mathrm{O}-\mathrm{H}$ and $\mathrm{N}-\mathrm{H}$ bonds. In the far infrared region, vibrations with large amplitude, such as torsional modes, ring puckering, crystal lattice vibrations and heavy 
atom skeletal bending modes, and molecular rotation are mainly observed. Information for the intermolecular forces is gained from the far IR spectra. Exemplary NIR and FIR spectra are presented in Figure 4. In Figure 4a, ranges characteristic for overtone bands characteristic of excited vibrational states and combined bands that are the sum of other fundamental vibrations are marked.

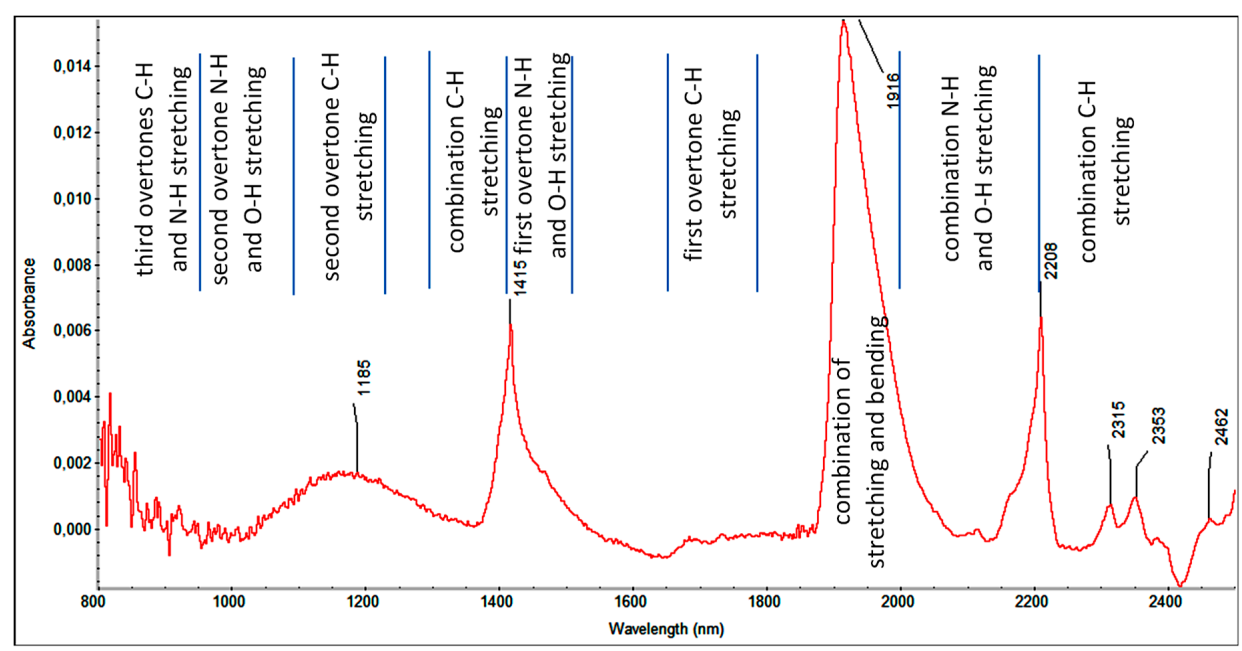

(a)

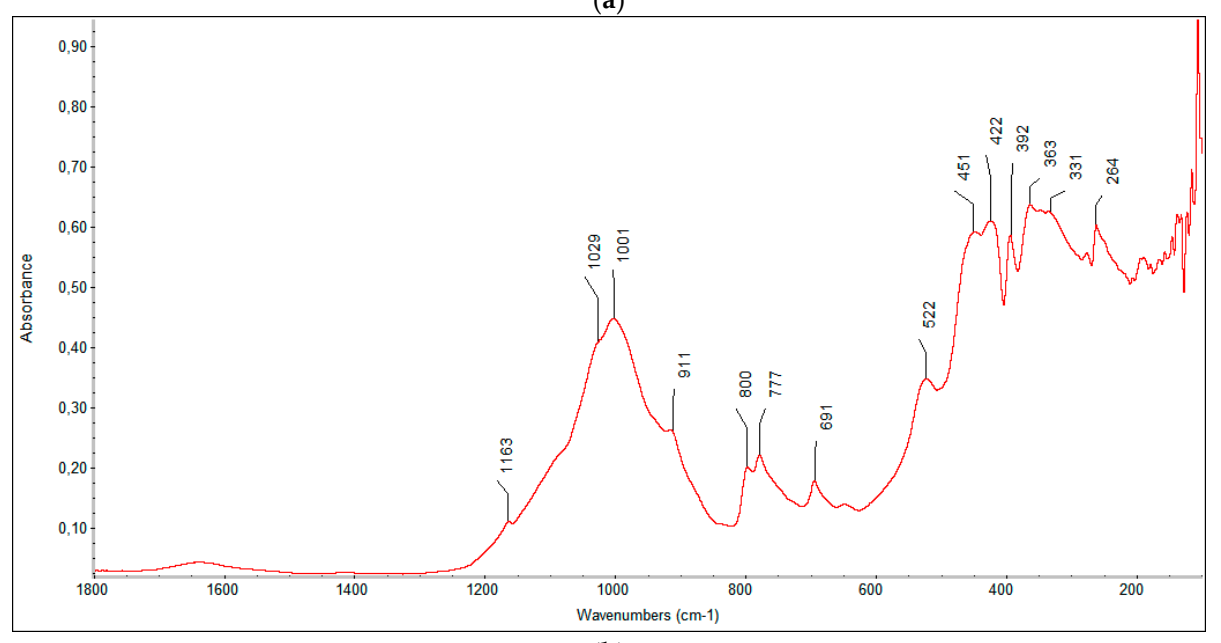

(b)

Figure 4. Exemplary (a) near infrared (NIR) and (b) far infrared (FIR) spectra.

The detailed interpretation of each band is impossible in such a complex sample. Moreover, the presence of metals in a soil usually does not result in the appearance of new peaks in the spectrum. Thus, the direct calibration and quantitative analysis of the metal concentration on the basis of the IR spectra is impossible. However, metals impact the IR spectra of soils and observed spectral changes can be used to measure metal concentration with the support of chemometric methods. The presence of complexes of functional groups, especially complexes containing oxygen with metal ions, causes frequency shifting and changes in the intensity and shape of bands, which can be used in the analysis of the metal concentration in soil samples. Metal bonding in organometallic compounds weakens the bonds and results in a lowering of the wavenumber value compared to the free groups. The crystal structure of the inorganic compounds can be affected in the presence of heavier cations, causing changes in the far IR. The PLS method enables one to investigate the relationship between the metal concentration in soil samples and the measured FT-IR spectra. 


\subsection{PLS Models for NIR, MIR, and FIR}

For effective investigation of the impact of the metal concentration in soil samples on the infrared spectra collected in the near, mid, and far infrared regions, PLS models were constructed. The PLS models described the relationship between 13 metals in soil (dependent variable $\mathbf{y}$ ), respectively, with spectral data organized in the matrix $\mathbf{X}$ containing the value of the spectral signal measured for different wavenumbers. The PLS models constructed for studying the metal concentration based on separate spectroscopic measurements in the NIR, MIR, and FIR regions are presented in Figures 5-7. The calculated RMS and RMSCV for the constructed PLS models are presented in Tables 1-3.
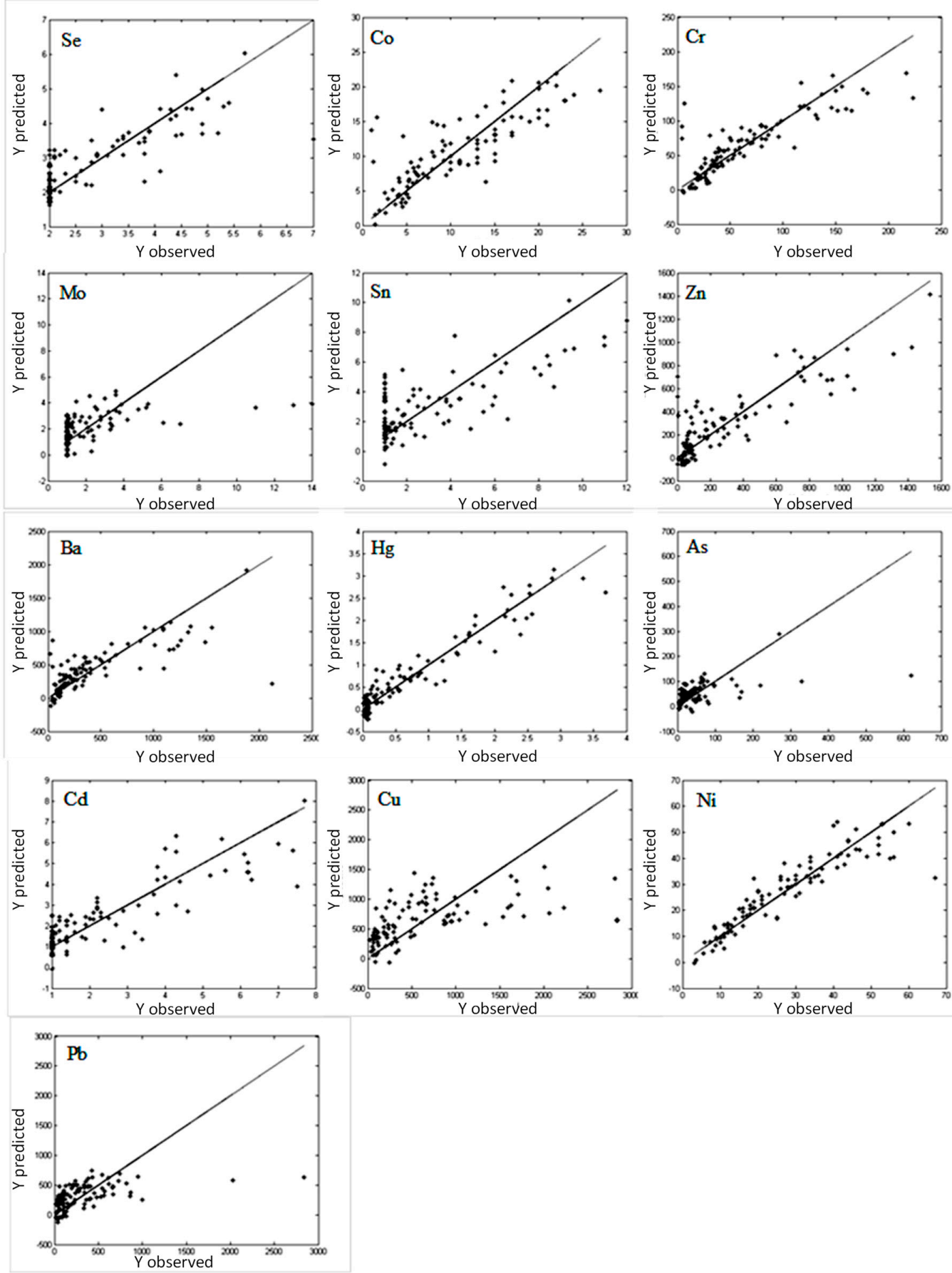

Figure 5. The PLS model describing the relationship between the metal content in soil and the spectral data measured using the ATR in the FIR. 

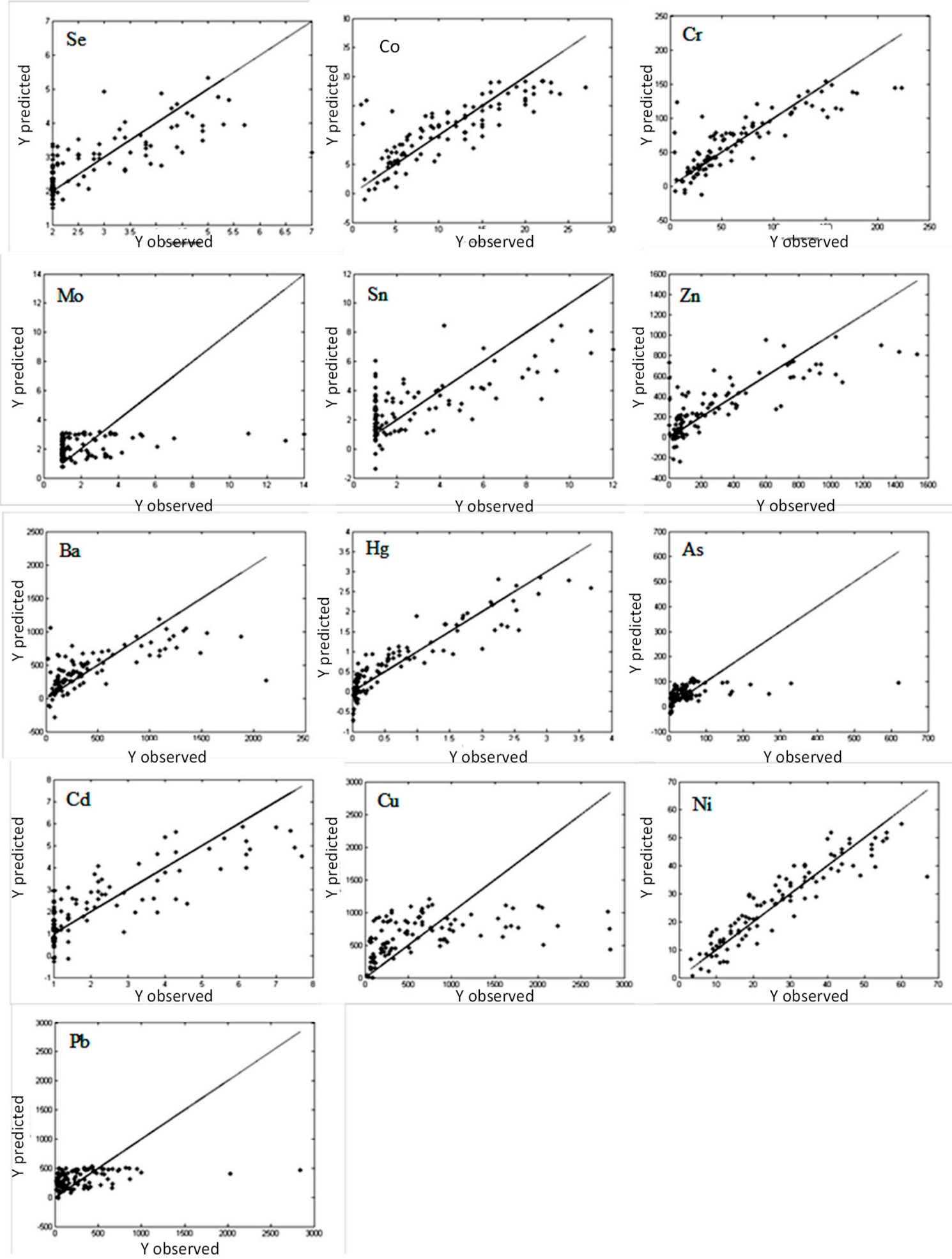

Figure 6. The PLS model describing the relationship between the metal content in soil and spectral data measured using the DRIFT in the MIR. 

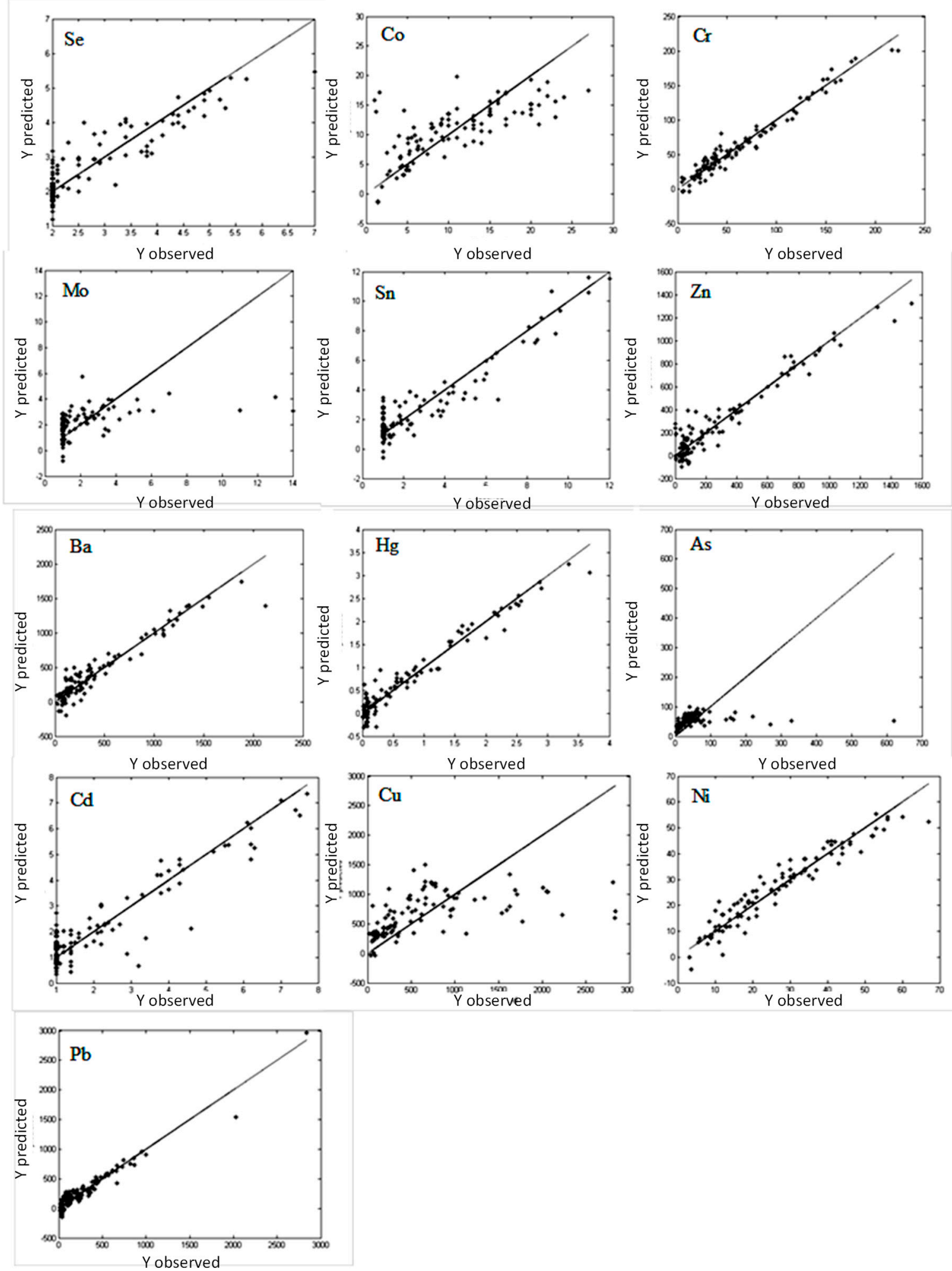

Figure 7. The PLS model describing the relationship between the metal content in soil and spectral data measured using the Near Integrated Sphere and DRIFT technique in the NIR. 
Table 1. The root mean square error (RMS) and root mean square error of cross validation (RMSCV) values for the PLS model based on ATR data in the FIR.

\begin{tabular}{c|c|c|c|c|c|c|c}
\hline Metals & Unit & Range & $\begin{array}{c}\text { Number } \\
\text { of } \\
\text { Variables }\end{array}$ & RMS & RMSCV & $\begin{array}{c}\text { \% } \\
\text { RMS }\end{array}$ & $\begin{array}{c}\% \\
\text { RMSCV }\end{array}$ \\
\hline $\mathrm{Co}$ & $\mathrm{mg} / \mathrm{kg}$ & {$[1.00,27.00]$} & 5 & 3.5826 & 4.1119 & 13.78 & 15.82 \\
$\mathrm{Cr}$ & $\mathrm{mg} / \mathrm{kg}$ & {$[4.10,223.00]$} & 4 & 25.5573 & 31.5102 & 11.68 & 14.39 \\
$\mathrm{Mo}$ & $\mathrm{mg} / \mathrm{kg}$ & {$[1.00,14.00]$} & 4 & 1.9542 & 2.2132 & 15.03 & 17.02 \\
$\mathrm{Sn}$ & $\mathrm{mg} / \mathrm{kg}$ & {$[1.00,12.00]$} & 5 & 1.8397 & 2.1310 & 16.72 & 19.37 \\
$\mathrm{Zn}$ & $\mathrm{mg} / \mathrm{kg}$ & {$[1.00,1530.00]$} & 5 & 183.5097 & 244.4817 & 12.00 & 15.99 \\
$\mathrm{Ba}$ & $\mathrm{mg} / \mathrm{kg}$ & {$[22.00,2120.00]$} & 5 & 293.3098 & 351.6731 & 13.98 & 16.76 \\
$\mathrm{Hg}$ & $\mathrm{mg} / \mathrm{kg}$ & {$[0.01,3.68]$} & 10 & 0.2729 & 0.3954 & 7.44 & 10.77 \\
$\mathrm{As}$ & $\mathrm{mg} / \mathrm{kg}$ & {$[4.00,620.00]$} & 4 & 66.5027 & 73.4838 & 10.80 & 11.93 \\
$\mathrm{Cd}$ & $\mathrm{mg} / \mathrm{kg}$ & {$[1.00,7.70]$} & 7 & 0.9147 & 1.1523 & 13.65 & 17.20 \\
$\mathrm{Cu}$ & $\mathrm{mg} / \mathrm{kg}$ & {$[22.00,2840.00]$} & 4 & 550.7588 & 601.2048 & 19.54 & 21.33 \\
$\mathrm{Ni}$ & $\mathrm{mg} / \mathrm{kg}$ & {$[3.10,67.00]$} & 5 & 6.0862 & 6.9554 & 9.52 & 10.88 \\
$\mathrm{~Pb}$ & $\mathrm{mg} / \mathrm{kg}$ & {$[18.00,2840.00]$} & 4 & 337.6865 & 368.6658 & 11.97 & 13.06 \\
$\mathrm{Se}$ & $\mathrm{mg} / \mathrm{kg}$ & {$[2.00,7.00]$} & 6 & 0.6485 & 0.7706 & 12.97 & 15.41 \\
\hline
\end{tabular}

Table 2. The RMS and RMSCV values for the PLS model based on DRIFT data in the MIR.

\begin{tabular}{|c|c|c|c|c|c|c|c|}
\hline Metals & Unit & Range & $\begin{array}{c}\text { Number } \\
\text { of } \\
\text { Variables }\end{array}$ & RMS & RMSCV & $\begin{array}{c}\% \\
\text { RMS }\end{array}$ & $\begin{array}{c}\% \\
\text { RMSCV }\end{array}$ \\
\hline Co & $\mathrm{mg} / \mathrm{kg}$ & {$[1.00,27.00]$} & 8 & 3.7606 & 4.4483 & 14.46 & 17.11 \\
\hline $\mathrm{Cr}$ & $\mathrm{mg} / \mathrm{kg}$ & {$[4.10,223.00]$} & 9 & 26.4988 & 33.0388 & 12.11 & 15.09 \\
\hline Mo & $\mathrm{mg} / \mathrm{kg}$ & {$[1.00,14.00]$} & 3 & 2.1376 & 2.2116 & 16.44 & 17.01 \\
\hline Sn & $\mathrm{mg} / \mathrm{kg}$ & {$[1.00,12.00]$} & 7 & 1.9682 & 2.2370 & 17.89 & 20.34 \\
\hline $\mathrm{Zn}$ & $\mathrm{mg} / \mathrm{kg}$ & {$[1.00,1530.00]$} & 7 & 215.4163 & 254.7562 & 14.09 & 16.66 \\
\hline $\mathrm{Ba}$ & $\mathrm{mg} / \mathrm{kg}$ & {$[22.00,2120.00]$} & 6 & 330.3738 & 386.9383 & 15.75 & 18.44 \\
\hline $\mathrm{Hg}$ & $\mathrm{mg} / \mathrm{kg}$ & {$[0.01,3.68]$} & 12 & 0.3643 & 0.5201 & 9.93 & 14.17 \\
\hline As & $\mathrm{mg} / \mathrm{kg}$ & {$[4.00,620.00]$} & 4 & 71.8133 & 75.3721 & 11.66 & 12.24 \\
\hline $\mathrm{Cd}$ & $\mathrm{mg} / \mathrm{kg}$ & {$[1.00,7.70]$} & 9 & 1.0321 & 1.3691 & 15.40 & 20.43 \\
\hline $\mathrm{Cu}$ & $\mathrm{mg} / \mathrm{kg}$ & {$[22.00,2840.00]$} & 4 & 593.1701 & 631.7240 & 21.05 & 22.42 \\
\hline $\mathrm{Ni}$ & $\mathrm{mg} / \mathrm{kg}$ & {$[3.10,67.00]$} & 11 & 5.9458 & 7.9458 & 9.30 & 12.43 \\
\hline $\mathrm{Pb}$ & $\mathrm{mg} / \mathrm{kg}$ & {$[18.00,2840.00]$} & 3 & 363.9935 & 376.5499 & 12.90 & 13.34 \\
\hline Se & $\mathrm{mg} / \mathrm{kg}$ & {$[2.00,7.00]$} & 7 & 0.7632 & 0.8864 & 15.26 & 17.73 \\
\hline
\end{tabular}

Table 3. The RMS and RMSCV values for the PLS model based on ATR data in the NIR.

\begin{tabular}{c|c|c|c|c|c|c|c}
\hline Metals & Unit & Range & $\begin{array}{c}\text { Number } \\
\text { of } \\
\text { Variables }\end{array}$ & RMS & RMSCV & $\begin{array}{c}\text { \% } \\
\text { RMS }\end{array}$ & $\begin{array}{c}\% \\
\text { RMSCV }\end{array}$ \\
\hline $\mathrm{Co}$ & $\mathrm{mg} / \mathrm{kg}$ & {$[1.00,27.00]$} & 4 & 4.4228 & 4.7491 & 17.01 & 18.27 \\
$\mathrm{Cr}$ & $\mathrm{mg} / \mathrm{kg}$ & {$[4.10,223.00]$} & 10 & 9.8576 & 31.5702 & 4.50 & 14.42 \\
$\mathrm{Mo}$ & $\mathrm{mg} / \mathrm{kg}$ & {$[1.00,14.00]$} & 6 & 1.9733 & 2.1884 & 15.18 & 16.83 \\
$\mathrm{Sn}$ & $\mathrm{mg} / \mathrm{kg}$ & {$[1.00,12.00]$} & 9 & 0.9858 & 2.2671 & 8.96 & 20.61 \\
$\mathrm{Zn}$ & $\mathrm{mg} / \mathrm{kg}$ & {$[1.00,1530.00]$} & 9 & 97.0534 & 224.6956 & 6.35 & 14.70 \\
$\mathrm{Ba}$ & $\mathrm{mg} / \mathrm{kg}$ & {$[22.00,2120.00]$} & 10 & 135.9009 & 363.9009 & 6.48 & 17.35 \\
$\mathrm{Hg}$ & $\mathrm{mg} / \mathrm{kg}$ & {$[0.01,3.68]$} & 9 & 0.2096 & 0.4168 & 5.71 & 11.36 \\
$\mathrm{As}$ & $\mathrm{mg} / \mathrm{kg}$ & {$[4.00,620.00]$} & 1 & 75.3621 & 76.3621 & 12.23 & 12.40 \\
$\mathrm{Cd}$ & $\mathrm{mg} / \mathrm{kg}$ & {$[1.00,7.70]$} & 9 & 0.6850 & 1.2343 & 10.22 & 18.42 \\
$\mathrm{Cu}$ & $\mathrm{mg} / \mathrm{kg}$ & {$[22.00,2840.00]$} & 1 & 562.4353 & 573.5291 & 19.96 & 20.35 \\
$\mathrm{Ni}$ & $\mathrm{mg} / \mathrm{kg}$ & {$[3.10,67.00]$} & 8 & 4.3375 & 6.9293 & 6.79 & 10.84 \\
$\mathrm{~Pb}$ & $\mathrm{mg} / \mathrm{kg}$ & {$[18.00,2840.00]$} & 10 & 96.2981 & 348.2871 & 3.41 & 12.34 \\
$\mathrm{Se}$ & $\mathrm{mg} / \mathrm{kg}$ & {$[2.00,7.00]$} & 8 & 0.4981 & 0.8552 & 9.96 & 17.10 \\
\hline
\end{tabular}

The constructed PLS models were analyzed in terms of fit and prediction abilities. The constructed models describing the relationship between the concentration and DRIFT spectra in the mid IR region (Figure 6) were characterized by a good fit for cobalt, chromium, mercury, and nickel. Unfortunately, the constructed PLS models for molybdenum, tin, arsenic, copper, and linear correlation were characterized by a weak fit and weak prediction abilities. 
Comparison of results obtained using different infrared regions, namely, far infrared ATR $\left(1800-100 \mathrm{~cm}^{-1}\right)$, and mid infrared DRIFT $\left(4000-400 \mathrm{~cm}^{-1}\right)$, which are presented in Figures 5 and 6 and in Tables 1 and 2, indicate slightly better results for the far IR range (lower values of \%RMS and $\%$ RMSCV for every metal). This result confirmed that the crystal structure of inorganic compounds was affected in the presence of heavy metals, since heavy atom skeletal bending vibrations can be observed in the far IR range. However, differences between these two ranges were not large, which suggested that the common range of $1800-400 \mathrm{~cm}^{-1}$ was crucial for both ranges. In this range, interactions between metal ions and organic functional groups (carbonylic, phenolic, alcoholic, and $\pi$-bonds) are observed. Individual metals form complexes with organic groups of different energy. The stronger new bond with metal is, the weaker organic group becomes, which results in a wider frequency shift of the peak for the 'pure' organic group. The PLS models constructed for mercury and nickel were characterized by a relatively good fit and prediction abilities (the lowest RMS and RMSCV among all constructed models).

Calibration models describing the relationship between metal concentration and DRIFT spectra in the near IR are shown in Figure 7. In comparison to the previous results presented here and those obtained using FIR and MIR regions, in the case of the NIR region, a noticeable improvement in calibration and the \%RMS values is observed in the cases of chromium, tin, zinc, barium, lead, selenium, as well as in mercury and nickel. However, analysis of the \%RMSCV values indicates that the prediction possibilities for the NIR DRIFT calibration models were smaller. The error values \%RMSCV were within the range $10.84-20.61 \%$. The lowest values of \%RMS and \%RMSCV for the DRIFT NIR calibration models were achieved for mercury, nickel, and lead.

In Table 4, errors achieved for each range were compared.

Table 4. Comparison of RMS and RMSCV values for PLS models based on each infrared range. (highest values of errors were marked with dark colors).

\begin{tabular}{ccccccc}
\hline Metal/Error & \multicolumn{3}{c}{ RMS \% } & \multicolumn{3}{c}{ RMSCV \% } \\
\hline Range & FIR & MIR & NIR & FIR & MIR & NIR \\
\hline $\mathrm{Co}$ & 13.78 & 14.46 & 17.01 & 15.82 & 17.11 & 18.27 \\
$\mathrm{Cr}$ & 11.68 & 12.11 & 4.50 & 14.39 & 15.09 & 14.42 \\
$\mathrm{Mo}$ & 15.03 & 16.44 & 15.18 & 17.02 & 17.01 & 16.83 \\
$\mathrm{Sn}$ & 16.72 & 17.89 & 8.96 & 19.37 & 20.34 & 20.61 \\
$\mathrm{Zn}$ & 12.00 & 14.09 & 6.35 & 15.99 & 16.66 & 14.70 \\
$\mathrm{Ba}$ & 13.98 & 15.75 & 6.48 & 16.76 & 18.44 & 17.35 \\
$\mathrm{Hg}$ & 7.44 & 9.93 & 5.71 & 10.77 & 14.17 & 11.36 \\
$\mathrm{As}$ & 10.80 & 11.66 & 12.23 & 11.93 & 12.24 & 12.40 \\
$\mathrm{Cd}$ & 13.65 & 15.40 & 10.22 & 17.20 & 20.43 & 18.42 \\
$\mathrm{Cu}$ & 19.54 & 21.05 & 19.96 & 21.33 & 22.42 & 20.35 \\
$\mathrm{Ni}$ & 9.52 & 9.30 & 6.79 & 10.88 & 12.43 & 10.84 \\
$\mathrm{~Pb}$ & 11.97 & 12.90 & 3.41 & 13.06 & 13.34 & 12.34 \\
$\mathrm{Se}$ & 12.97 & 15.26 & 9.96 & 15.41 & 17.73 & 17.10 \\
\hline
\end{tabular}

Generally, all the investigated spectral techniques and infrared radiation ranges have similar applicability for analysis of the metal concentration in soil. However, results indicated that there were differences between models depending on IR ranges and metals.

The best results and errors below 10\% were achieved for following metals: chromium, zinc, barium, mercury, nickel, and lead. The highest linearity and lowest RMS values were achieved for the NIR range.

Models created using spectra measured in the far-IR region allowed us to get better linearity and lower RMS and RMSCV values there than for the MIR region. The model based on FIR spectra were characterized by better prediction abilities than NIR only in case of cobalt (\%RMS 13.78, \%RMSCV 15.82). For the other metals, application of FIR region did not improve possibilities of the models in 
comparison to the NIR region. The \%RMS values below $10 \%$ were achieved only for mercury $(7.44 \%)$ and nickel (9.52\%). The values of \%RMSCV for models based on FIR and NIR spectra were similar.

The satisfying model was not achieved for some metals like molybdenum and arsenic. Low concentrations of tin were impossible to predict, and a higher concentration of tin fair linearity and low RMS could only be observed in the NIR region. The outcome was similar for selenium - the linearity of the model was poor, especially for low concentrations. The model created for the copper was also not good - in the region of FIR and NIR for concentrations exceeding $1000 \mathrm{mg} / \mathrm{kg}$ predicted content was underestimated. For lower concentrations, NIR and FIR linearity was poor and there was a large spread of results. A similar observation was described for some heavy metals by Chodak et al. [9] and Siebielec et al. [10]. They concluded that such underestimated results of high concentrations were due to the fact that heavy metals in industrial samples are partially present in the inorganic form.

Comparison of the obtained results to the literature is difficult because of the broader scope of this paper (13 metals) and the much higher metal concentrations used. For example, Gholizadeh et al. (2015) considered the following ranges of concentrations in $\mathrm{mg} / \mathrm{kg}$ : $\mathrm{Cu} 5.5$ to $92.24, \mathrm{Cd} 0.01$ to 0.73, $\mathrm{Pb} 0.90$ to 49.60, Zn 6.60 to 213.11, and As 0 to 19. Maximum contents of this metals in this paper were: $\mathrm{Cu}$ 2840, Cd 7.70, Pb 2840, Zn 1530, and As 620 mg/kg. Similarly, Chakraborty et al. (2015) for lead and Chen et al. (2015) for cadmium considered lower concentrations in soil. Chodak et al. (2007) investigated zinc concentration up to $4601 \mathrm{mg} / \mathrm{kg}$ which is much higher than in our paper. They reported a value of standard error of cross validation of 770 and a standard error of calibration of 436 . Our results could be partly compared to the results presented by Siebielec et al. (2004) for lead (max. ca. $2000 \mathrm{mg} / \mathrm{kg}$ - in our paper the equivalent is $2840 \mathrm{mg} / \mathrm{kg}$ ) and nickel (max. $80 \mathrm{mg} / \mathrm{kg}$ - in our paper $67 \mathrm{mg} / \mathrm{kg}$ ). They reported that root mean squared deviations in NIR/MIR range were 839/662 for lead and $6.21 / 1.88$ for nickel.

The spectroscopic methods were characterized by higher values for the calibration and prediction errors than the reference techniques, i.e., the error values usually exceeded $10 \%$. The described method based on the FT-IR spectra is not an alternative to the ICP-OES method but rather can be perceived as a supplementary method with great potential for application in the estimation and approximate monitoring of soil contamination in large areas.

\section{Conclusions}

The application of FT-IR enables the simultaneous determination of several harmful metals in soil samples, which impacts the cost, speed, and effectiveness of environmental monitoring. The accuracy achieved with this method was good, but lower than that realized using conventional laboratory analyses. Such results indicated that FT-IR can be considered as a supplementary method to other traditionally used instrumental methods for determining metal content, such as ICP-OES. The PLS models constructed from the FT-IR spectra for the studied dataset were useful in the estimation of soil contamination by heavy metals. The results obtained indicated that both spectral techniques, namely, attenuated total reflectance (ATR) and diffuse reflectance (DRIFT), and spectra collected to each spectral region, namely far-IR, mid-IR and near-IR, enabled the construction of proper calibration models for a large number of samples for a single region for following metals: $\mathrm{Cr}, \mathrm{Zn}, \mathrm{Ba}, \mathrm{Hg}, \mathrm{Ni}$, and $\mathrm{Pb}$. Application of spectra for the far-IR slightly improved the prediction possibilities of the model in comparison to the mid-IR region. The models based on NIR-spectra were characterized by slightly better linearity than other ranges and the lowest RMS values. Attempts to create good models failed for several metals: Mo, Sn, As, Se, and $\mathrm{Cu}$. Taking into account calibration and prediction errors, FT-IR spectroscopy could be applied in the monitoring of changes over time regarding heavy metal concentrations or the mapping of contamination levels across large areas.

Author Contributions: Conceptualization, A.Ś. and A.S.; methodology, A.Ś.; validation, A.Ś. and P.K.; formal analysis, A.Ś. and A.S.; investigation, A.Ś. and A.S. data curation, A.S.; writing—original draft preparation, A.Ś. and P.K.; writing—review and editing, A.Ś.; visualization, A.Ś. and A.S.; supervision, A.S. 
Funding: The research work was supported by the Ministry of Science and Higher Education within the Research Project no 11110117-321.

Acknowledgments: We would like to thank the team of the Laboratory of Solid Waste Analyses of the Central Mining Institute and especially Marek Stempin for advice, performing analyses and providing samples.

Conflicts of Interest: The authors declare no conflict of interest.

\section{References}

1. European Parliament, Council of the European Union. 2010/75/EU of the European Parliament and of the Council of 24 November 2010 on Industrial Emissions (Integrated Pollution Prevention and Control). 2010. Available online: https://eur-lex.europa.eu/homepage.html (accessed on 5 November 2019).

2. Rozporzadzenie Ministra Środowiska z Dnia 1 Września 2016 r. w Sprawie Sposobu Prowadzenia Oceny Zanieczyszczenia Powierzchni Ziemi; Warsaw, Poland, 2016. Available online: http://prawo.sejm.gov.pl/ isap.nsf/DocDetails.xsp?id=WDU20160001395 (accessed on 5 November 2019).

3. Alloway, B.J. Heavy Metals in Soils. In Trace Metals and Metalloids in Soils and Their Bioavailability; Springer: New York, NY, USA, 2010.

4. Tinti, A.; Tughnoli, V.; Bonora, S.; Francioso, O. Recent applications of vibrational mid-infrared (IR) spectroscopy for studying soil components: A review. J. Cent. Eur. Agric. 2015, 16, 1-22. [CrossRef]

5. Nocita, M.; Stevens, A.; Wesemael, B.; Aitkenhead, M.; Bachmann, M. Soil Spectroscopy: An Alternative to Wet Chemistry for Soil Monitoring. Adv. Agron. 2015, 132, 139-159.

6. Shepherd, K.D.; Walsh, M.G. Infrared spectroscopy—enabling an evidence-based diagnostic surveillance approach to agricultural and environmental management in developing countries. J. Near Infrared Spectrosc. 2007, 15, 1-19. [CrossRef]

7. Viscarra Rossel, R.A.; Walvoort, D.J.J.; McBratney, A.B.; Janik, L.J.; Skjemstad, J.O. Visible, near infrared, mid infrared or combined diffuse reflectance spectroscopy for simultaneous assessment of various soil properties. Geoderma 2006, 131, 59-75. [CrossRef]

8. Ng, W.; Malone, B.; Minasny, B. Rapid assessment of petroleum-contaminated soils with infrared spectroscopy. Geoderma 2017, 289, 150-160. [CrossRef]

9. Chodak, M.; Niklińska, M.; Beese, F. Near-infrared spectroscopy for analysis of chemical and microbiological properties of forest soil organic horizons in a heavy-metal-polluted area. Biol. Fertil. Soils 2007, 44, 171-180. [CrossRef]

10. Siebielec, G.; McCarty, G.W.; Stuczynski, T.I.; Reeves, J.B. Near-and Mid-Infrared Diffuse Reflectance Spectroscopy for Measuring Soil Metal Content. J. Environ. Qual. 2004, 33, 2056-2069. [CrossRef] [PubMed]

11. Gholizadeh, A.; Borůvka, L.; Saberioon, M. A spectroscopic approach to assess potentially toxic elements of reclaimed dumsites in the Czech Republic. Int. J. Environ. Sci. Dev. 2015, 6, 571-575. [CrossRef]

12. Chen, T.; Chang, Q.; Clevers, J.G.P.W.; Kooistra, L. Rapid identification of soil cadmium pollution risk at regional scale based on visible and near-infrared spectroscopy. Environ. Pollut. 2015, 206, 217-226. [CrossRef]

13. Niazi, N.K.; Singh, B.; Minasny, B. Mid-infrared spectroscopy and partial least-squares regression to estimate soil arsnic at a highly variable arsenic-contaminated site. Int. J. Environ. Sci. Technol. 2015, 12, 1965-1974. [CrossRef]

14. Chakraborty, S.; Weindorf, D.C.; Paul, S.; Ghosh, B.; Li, B.; Ali, N.; Ghosh, R.K.; Ray, D.P.; Majumdar, K. Diffuse reflectance spectroscopy for monitoring lead in landfill agricultural soils of India. Geoderma Reg. 2015, 5, 77-85. [CrossRef]

15. Xu, D.; Zhao, R.; Li, S.; Chen, S.; Jiang, Q.; Zhou, L.; Shi, Z. Multi-sensor fusion for the determination of several soil properties in the Yangtze River Delta, China. Eur. J. Soil Sci. 2019, 70, 162-173. [CrossRef]

16. Jiminez-Donaire, V.; Kuang, B.; Waine, T.; Mouazen, A. On-line visible and near infrared (vis-NIR) measurement of key soil fertility parameters in vegetable crop fields. Proc. Int. Conf. Agric. Eng. 2014, 07, 6-10.

17. He, Y.; Song, H.; Pereira, A.G.; Gómez, A.H. Measurement and analysis of soil nitrogen and organic matter content using near-infrared spectroscopy techniques. J. Zgejiang Univ. Sci. 2005, 6, 1081-1086. [CrossRef] [PubMed]

18. Martin, P.D.; Malley, D.F.; Manning, G.; Fuller, L. Determination of soil organic carbon and nitrogen at the field level using near-infrared spectroscopy. Can. J. Soil Sci. 2015, 82, 413-422. [CrossRef] 
19. Reeves, J.B. Near-versus mid-infrared diffuse reflectance spectroscopy for soil analysis emphasizing carbon and laboratory versus on-site analysis: Where are we and what needs to be done? Geoderma 2010, 158, 3-14. [CrossRef]

20. D'Acqui, L.P.; Pucci, A.; Janik, L.J. Soil properties prediction of western Mediterranean islands with similar climatic environments by means of mid-infrared diffuse reflectance spectroscopy. Eur. J. Soil Sci. 2010, 61, 865-876. [CrossRef]

21. Ma, F.; Du, C.W.; Zhou, J.M.; Shen, Y.Z. Investigation of soil properties using different techniques of mid-infrared spectroscopy. Eur. J. Soil Sci. 2018, 70, 96-106. [CrossRef]

22. Djaković-Sekulić, T.; Smoliński, A. Chemometric characterization of s-triazine derivatives in relation to structural parameters and biological activity. Drug Dev. Ind. Pharm. 2010, 36, 954-961. [CrossRef]

23. Jensen, M.E.; Bourgeron, P.S. A Guidebook for Integrated Ecological Assessments; Springer: New York, NY, USA, 2001.

24. Smoliński, A.; Walczak, B. Robust multivariate calibration in environmental studies. Anal. Lett. 2003, 36, 2317-2336. [CrossRef]

25. Wold, H. Soft Modeling: The Basic Design and Some Extensions, Systems Under Indirect Observation. In Causality-Structure-Prediction; North-Holland: Amsterdam, The Netherlands, 1981.

26. Wold, S.; Martens, H.; Wold, H. The Multivariate Calibration Problem in Chemistry Solved by the PLS Method. In Lecture Notes in Mathematics; Springer: Heidelberg, Germany, 1983.

27. Martens, H.; Naes, T. Multivariate Calibration; John Wiley \& Sons: New York, NY, USA, 1989.

28. Smoliński, A.; Zołotajkin, M.; Ciba, J.; Dydo, P.; Kluczka, J. Robust PLS Regression Models to Predict Aluminum Content in Soils of Beskid Mountains Region. Chemosphere 2009, 76, 565-571. [CrossRef] [PubMed]

29. Wold, S. Cross-validatory estimation of the number of components in factor and principal components models. Technometrics 1978, 20, 397-406. [CrossRef]

30. Stuart, B. Infrared Spectroscopy: Fundamentals and Applications; John Wiley \& Sons: New York, NY, USA, 2004.

31. Shafeeyan, M.S.; Daud, W.M.A.W.; Houshmand, A.; Shamiri, A. A review on surface modification of activated carbon for carbon dioxide adsorption. J. Anal. Appl. Pyrolysis 2010, 89, 143-151. [CrossRef] 